\title{
Cardiovascular risk factor control is insufficient in young patients with coronary artery disease
}

\author{
This article was published in the following Dove Press journal: \\ Vascular Health and Risk Management \\ 25 May 2016 \\ Number of times this article has been viewed
}

\section{Morten Krogh Christiansen Jesper Møller Jensen Anders Krogh Brøndberg Hans Erik Bøtker Henrik Kjærulf Jensen \\ Department of Cardiology, Aarhus University Hospital, Aarhus, Denmark}

Correspondence: Morten Krogh Christiansen

Department of Cardiology, Aarhus University Hospital, Palle Juul-Jensens Boulevard 99, 8200 Aarhus N, Denmark Tel +457845 2267

Fax +4578452260

Email morten.christiansen@clin.au.dk
Background: Control of cardiovascular risk factor is important in secondary prevention of coronary artery disease (CAD) but it is unknown whether treatment targets are achieved in young patients. We aimed to examine the prevalence and control of risk factors in this subset of patients. Methods: We performed a cross-sectional, single-center study on patients with documented CAD before age 40. All patients treated between 2002 and 2014 were invited to participate at least 6 months after the last coronary intervention. We included 143 patients and recorded the family history of cardiovascular disease, physical activity level, smoking status, body mass index, waist circumference, blood pressure, cholesterol levels, metabolic status, and current medical therapy. Risk factor control and treatment targets were evaluated according to the shared guidelines from the European Society of Cardiology.

Results: The most common insufficiently controlled risk factors were overweight (113 [79.0\%]), low-density lipoprotein cholesterol above target (77 [57.9\%]), low physical activity level (78 [54.6\%]), hypertriglyceridemia (67 [46.9\%]), and current smoking (53 [37.1\%]). Almost onehalf of the patients fulfilled the criteria of metabolic syndrome. The median (interquartile range) number of uncontrolled modifiable risk factors was $2(2 ; 4)$ and only seven $(4.9 \%)$ patients fulfilled all modifiable health measure targets.

Conclusion: Among the youngest patients with $\mathrm{CAD}$, there remains a potential to improve the cardiovascular risk profile.

Keywords: coronary artery disease, cardiovascular diseases/prevention and control, health behavior, risk factors, young adult, middle aged

\section{Introduction}

Young patients with coronary artery disease (CAD) are characterized by a high burden of traditional risk factors with family predisposition, obesity, smoking, and dyslipidemia reported as being more frequent among younger compared with older individuals. ${ }^{1,2}$ Constituting only a minority of patients with CAD, young individuals with CAD are nevertheless important to identify because CAD remains the most common cause of sudden cardiac death in younger ages. ${ }^{3}$ While the short-term prognosis may be acceptable, life expectancy is far from that observed in identical age groups in the general population. ${ }^{4}$ Given compelling evidence of the effects of risk factor control and the potential years of morbidity and mortality to be saved among young patients with CAD, risk factor control in this subgroup of patients is of paramount importance.

The current shared guidelines from The Fifth Joint Task Force of the European Society of Cardiology and Other Societies on Cardiovascular Disease Prevention recommend a 
target-based approach regarding control of blood pressure, lipids, and diabetes in patients with established CAD as well as recommendations on smoking, weight, diet, and level of physical activity. ${ }^{5}$ However, a large proportion of patients with CAD do not reach targets for risk factor control. ${ }^{6,7} \mathrm{We}$ hypothesized that control of risk factors is insufficient in young patients with $\mathrm{CAD}$ and therefore we aimed to evaluate the prevalence and control of risk factors in these patients.

\section{Methods}

\section{Study population and design}

The current study was a cross-sectional study of young patients with CAD recruited from the Western Denmark Heart Registry. All medical records were reviewed on patients registered with percutaneous coronary intervention (PCI) or coronary artery bypass graft operations performed before the age of 40 years at Aarhus University Hospital between January 1, 2002 and December 31, 2013. Patients were eligible if they were alive and did not meet any of the exclusion criteria: 1) intervention on the basis of nonatherosclerotic disease (eg, coronary arteritis, embolism, intimal dissections); 2) heart transplant prior to first coronary intervention; 3) drug abuse within 1 week of the first intervention; and 4) current residency unknown or outside of Denmark.

All the eligible patients were invited by letter at least 6 months after the last coronary intervention. If no response was obtained, a second written attempt to contact the patient was made. Compliance with the study criteria was confirmed at a preliminary telephone interview and written informed consent was obtained from all participants upon attendance. The study was approved by the National Committee on Health Research Ethics.

\section{Patient interview}

We interviewed all the study patients in our outpatient clinic between February 1, 2014 and April 30, 2015. We collected information about medical history, lifestyle habits, symptoms, and current medical therapy at the time of CAD onset (defined as the time of the first coronary revascularization procedure) as well as at the time of study interview. All medical records were reviewed for confirmation. In case of disagreement between information obtained from the interview and the medical records, the disagreement was presented to the patient and his or her statement was accepted as valid.

Hypertension before CAD onset was considered present if a physician had previously diagnosed it. Dyslipidemia before $\mathrm{CAD}$ onset was considered present if a physician had previously diagnosed it or total cholesterol concentration or low-density lipoprotein cholesterol (LDL-C) exceeding $5.0 \mathrm{mM}$ or $3.0 \mathrm{mM}$, respectively, had been measured. Familial hypercholesterolemia (FH) was present if an assumed pathogenic mutation in the $L D L R, A P O B$, or PCSK9 gene was found. Diabetes was classified as type 1 or 2 , or of other types according to previous physician-made diagnoses. Type 2 diabetes diagnosed at study interview was categorized as undiagnosed, and guideline-based risk factor control targets were then evaluated as if the patient did not have diabetes.

Patients were categorized as current smokers when they had been smoking within the last month, former smokers when prior cumulated smoking exceeded 1 pack-year, and otherwise as nonsmokers.

Patients were interviewed about physical activity. The patient was presented with examples of moderate- and vigorous-intensity activity in daily work and leisure, which had been used in the Danish Health and Morbidity Survey (SUSY 2005), to estimate the number of days per week with exercise more than $30 \mathrm{~min} /$ day. ${ }^{8}$ An active as opposed to a sedentary lifestyle was defined as exercising at least 30 minutes $\geq 3$ times a week. ${ }^{5}$

A family history was obtained and premature CAD in relatives was defined as a diagnosis of CAD before the age of 55 years in males and 65 years in females, respectively.

Patients were interviewed about their health system contact patterns. Regular consultations about CAD risk factors were defined as visits at least once per year to the general practitioner and/or a specialist in internal medicine.

Information about invasive treatment(s), echocardiographic assessment(s), and degree of CAD was collected from medical records.

\section{Physical examination}

Automated office blood pressure measurement (AOBP) was performed using the BpTRU device (BpTRU Medical Devices Inc., Coquitlam, BC, Canada). ${ }^{9}$ Blood pressure was categorized as low normal $(<120 / 80 \mathrm{mmHg})$, high normal (120-140/80-90 mmHg), stage 1 hypertension (140-160/90$100 \mathrm{mmHg}$ ), stage 2 hypertension (160-180/100-110 $\mathrm{mmHg}$ ), and stage 3 hypertension ( $\geq 180 / 110 \mathrm{mmHg}$ ).

Height, weight, and waist circumference were measured and the body mass index (BMI) was calculated. The patients were categorized according to the definitions of the World Health Organization as underweight $\left(<18.5 \mathrm{~kg} / \mathrm{m}^{2}\right)$, normal weight (18.5-25 kg/m²), overweight $\left(25-30 \mathrm{~kg} / \mathrm{m}^{2}\right)$, or obese $\left(\geq 30 \mathrm{~kg} / \mathrm{m}^{2}\right)$, and abdominal obesity was defined as $\geq 102 \mathrm{~cm}$ in males and $\geq 88 \mathrm{~cm}$ in females. 
A blood sample was collected for determining the concentrations of creatinine, hemoglobin A1c ( $\mathrm{HbAlc}$ ), total cholesterol, high-density lipoprotein cholesterol (HDL-C) and triglycerides. In cases of triglycerides $<4 \mathrm{mM}$, LDL-C was calculated using the Friedewald formula (otherwise recorded as missing). If available, cholesterol levels prior to lipid-lowering treatment were recorded.

The presence of metabolic syndrome was defined according to the International Diabetes Federation consensus worldwide definition of the metabolic syndrome ${ }^{10}$; however, fasting glucose was omitted as a criterion because it was not measured. Hence, the definition of the metabolic syndrome was a waist circumference $\geq 94 \mathrm{~cm}$ for males and $\geq 80 \mathrm{~cm}$ for females plus any two of the following: 1) triglycerides $\geq 1.7 \mathrm{mM}$; 2) HDL-C $<1.0 \mathrm{mM}$ in males and $<1.3 \mathrm{mM}$ in females; 3) systolic AOBP $\geq 130 \mathrm{mmHg}$ or diastolic AOBP $\geq 85 \mathrm{mmHg}$, or the known antihypertensive treatment; and 4) the presence of type 2 diabetes.

\section{Treatment targets}

We used the recommendations by the European guidelines on cardiovascular disease prevention ${ }^{5}$ to define risk factor control. Accordingly, optimal risk factor control was defined as follows: 1) a BMI $<25 \mathrm{~kg} / \mathrm{m}^{2} ; 2$ ) waist circumference $<102 \mathrm{~cm}$ in males and $<88 \mathrm{~cm}$ in females; 3) moderate- or vigorous-intensity exercise for at least 30 minutes $\geq 3$ times a week; 4 ) no current smoking; 5) systolic blood pressure $<140 \mathrm{mmHg}$ and diastolic blood pressure $<90 \mathrm{mmHg}$ (in diabetics, blood pressure was considered elevated if $\geq 140 / 80 \mathrm{mmHg}$ ); 6 ) a LDL-C $<1.8 \mathrm{mM}$ or, if available, a reduction of at least $50 \%$ from the untreated value; and 7) a $\mathrm{HbAlc}$ value $<53 \mathrm{mmol} / \mathrm{mol}$. The primary outcome measure was the number of uncontrolled risk factors.

\section{Statistical analyses}

Statistical analyses were performed using STATA/IC 13.1 (StataCorp, College Station, TX, USA). Discrete variables are presented as numbers (percentages) and continuous variables as mean (standard deviation) if normally distributed, otherwise as median (interquartile range [IQR]). Comparisons of discrete variables were performed using Fisher's exact test or chisquare statistics, while Wilcoxon's rank-sum test or Student's $t$-test were applied on continuous variables, as appropriate.

\section{Results}

The selection of patients is shown in Figure 1. A total of 358 patients were registered with coronary intervention before the age of 40 years. After reviewing the medical records, 75 were adjudicated as noneligible (outlined in Figure 1), leaving 283 patients, of which 143 (50.5\%) agreed to participate in the study. To address if a potential selection bias had occurred, data from the first registered coronary intervention entered into the Western Denmark Heart Registry between January 1, 2002 and December 31, 2013 were compared between participating patients and eligible nonparticipating patients. We identified no differences (Table S1) by comparing age, sex, revascularization strategy (PCI vs coronary artery bypass graft), indication for PCI, the number of diseased vessels at PCI, current smoking, antihypertensive treatment, lipid-lowering treatment, diabetes status, BMI, and levels of creatinine. A family history of $\mathrm{CAD}$, however, was slightly more common among patients compared with those who declined participation ( 86 [64.2\%] vs 63 [49.6\%], $P=0.02$ ).

\section{Risk factors at CAD onset}

Median (IQR) age at onset of CAD was 37 years $(34 ; 38)$ and $110(76.9 \%)$ were males. At onset, $113(79.0 \%)$ presented with acute myocardial infarction and $107(74.8 \%)$ had one vessel disease. Smoking was the most prevalent risk factor present in 104 (72.7\%) individuals, whereas a diagnosis of dyslipidemia, hypertension, and diabetes had been made in $40(28.0 \%), 23(16.1 \%)$, and $12(8.4 \%)$ patients, respectively. All risk factors were evenly distributed between females and males, however, diabetes was seen more in females than in males (seven [21.2\%] vs five [4.6\%], $P<0.01$ ).

\section{Risk factors at interview}

The median (IQR) age at interview was $44(41 ; 47)$ years, a median of 5.6 years after the last coronary intervention (Table 1). Family history was available for 140 patients of whom $46(32.9 \%)$ had at least one first degree relative

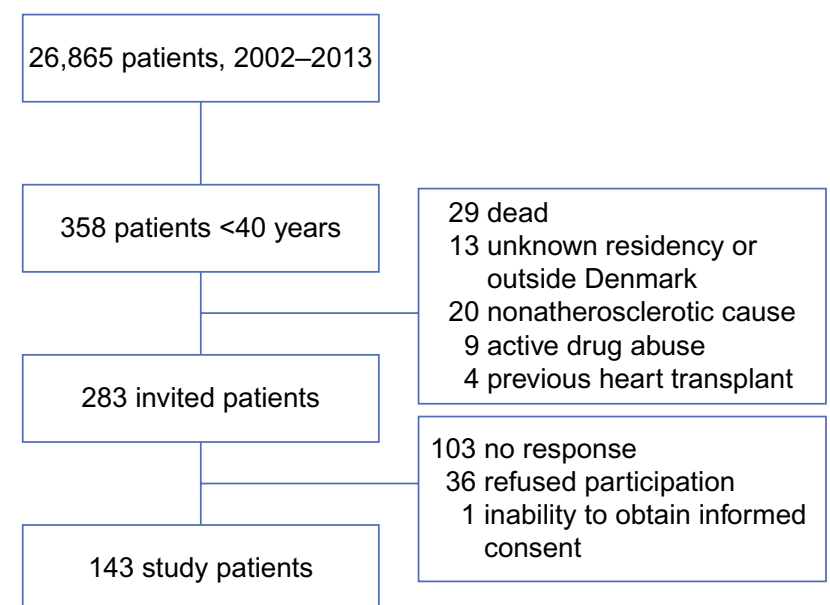

Figure I Patient selection. 
Table I Characteristics of the patients at study interview

\begin{tabular}{|c|c|c|c|c|}
\hline Characteristics & Total $(n=143)$ & Male $(n=I \mid 0)$ & Female $(n=33)$ & $P$-value \\
\hline Age, years & $44(4 I ; 47)$ & $43(4 I ; 47)$ & $45(40 ; 48)$ & 0.40 \\
\hline Years since last coronary event & $5.6(2.1 ; 8.9)$ & $5.6(2.4 ; 8.7)$ & $6.4(1.9 ; 10.5)$ & 0.55 \\
\hline Diseased vessels & & & & 0.05 \\
\hline IVD & $91(63.6)$ & $64(58.2)$ & $27(81.8)$ & \\
\hline 2VD & $26(18.2)$ & $23(20.9)$ & $3(9.1)$ & \\
\hline $3 V D$ & $26(18.2)$ & $23(20.9)$ & $3(9.1)$ & \\
\hline Last estimate of LVEF (\%) & $60(50 ; 60)$ & $60(50 ; 60)$ & $60(50 ; 60)$ & 0.98 \\
\hline \multicolumn{5}{|l|}{ Vascular comorbidity } \\
\hline Prior MI & $120(83.9)$ & $92(83.6)$ & $28(84.9)$ & 1.00 \\
\hline Prior stroke & II (7.7) & $7(6.4)$ & $4(12.1)$ & 0.28 \\
\hline PAD & $3(2.1)$ & $2(1.8)$ & I (3.0) & 0.55 \\
\hline \multicolumn{5}{|l|}{ Other comorbidity } \\
\hline Diabetes & $29(20.3)$ & $18(16.4)$ & II (33.3) & 0.03 \\
\hline $\mathrm{FH}$ & $8(5.6)$ & $6(5.5)$ & $2(6.1)$ & 1.00 \\
\hline Systolic BP (mmHg) & $122 \pm 14$ & $122 \pm 14$ & $123(13)$ & 0.49 \\
\hline Diastolic BP (mmHg) & $82 \pm 9$ & $83 \pm 10$ & $81(8)$ & 0.41 \\
\hline BMI $\left(\mathrm{kg} / \mathrm{m}^{2}\right)$ & & & & 0.01 \\
\hline$<18.5$ & $\mathrm{I}(0.7)$ & $\mathrm{I}(0.9)$ & $0(0)$ & \\
\hline $18.5-25$ & $29(20.3)$ & $16(14.6)$ & $13(39.4)$ & \\
\hline $25-30$ & $53(37.1)$ & $46(41.8)$ & $7(2 \mid .2)$ & \\
\hline$\geq 30$ & $60(42.0)$ & $47(42.7)$ & $13(39.4)$ & \\
\hline Waist (cm) & $101.4(92.1 ;|1| 2.2)$ & $103.9(93.2 ; 114.3)$ & $96.6(82.3 ; 103.2)$ & $<0.01$ \\
\hline \multicolumn{5}{|l|}{ Biochemistry } \\
\hline TC-C (mM) & $4.1(3.5 ; 5.1)$ & $4.1(3.4 ; 5.1)$ & $4.0(3.6 ; 4.8)$ & 0.81 \\
\hline HDL-C (mM) & I.I (I.0;I.4) & I.I $(0.9 ; 1.2)$ & $1.3(1.1 ; 1.6)$ & $<0.01$ \\
\hline LDL-C (mM) & $2.2(1.5 ; 2.7)$ & $2.2(1.5 ; 2.7)$ & $2.0(1.5 ; 2.7)$ & 0.40 \\
\hline Triglycerides (mM) & $1.5(1.0 ; 2.2)$ & $1.6(1.0 ; 2.2)$ & $1.4(1.0 ; 2.2)$ & 0.60 \\
\hline $\mathrm{HbAlc}(\mathrm{mmol} / \mathrm{mol})$ & $39(36 ; 42)$ & $38(36 ; 40)$ & $4 \mid(38 ; 50)$ & $<0.01$ \\
\hline Creatinine $(\mu \mathrm{M})$ & $78(68 ; 87)$ & $79(72 ; 87)$ & $66(59 ; 7 I)$ & $<0.01$ \\
\hline
\end{tabular}

Notes: Values are expressed as median (interquartile range), $\mathrm{n}(\%)$ or mean \pm standard deviation. aLDL-C was calculated in I33 patients.

Abbreviations: BMI, body mass index; BP, blood pressure; FH, familial hypercholesterolemia; HbAIc, hemoglobin A lc; HDL-C, high-density lipoprotein cholesterol; LDL-C, low-density lipoprotein cholesterol; LVEF, left ventricular ejection fraction; MI, myocardial infarction; PAD, peripheral artery disease; TC-C, total cholesterol concentration; VD, vessel disease.

with premature CAD. Sixty-nine patients (48.3\%) reported regular visits to their general practitioner for a CAD risk factor consultation, whereas 29 patients (20.3\%) visited a hospital or a specialist in internal medicine, and ten patients (7.0\%) reported to both. The majority of patients received antithrombotic or anticoagulant (138 [96.5\%]), antihypertensive (114 [79.7\%]) as well as lipid-lowering (121 [84.6\%]) therapy (Table 2).

\section{Control of risk factors at interview}

Health measures were generally poorly controlled (Table 3 ). The most prevalent risk factor was overweight $113(79.0 \%)$ and 76 (53.2\%) exhibited abdominal obesity. A BMI above $25 \mathrm{~kg} / \mathrm{m}^{2}$ was more common among males. By considering the sex-specific measures of abdominal obesity, we found no differences between males and females. More than one-half of the patients did not meet the guideline recommendation of exercising at least 30 minutes three times a week, but
$41(54.0 \%)$ of these patients reported that they had made attempts to increase exercise to the recommended level. More than one-third (53 [37.1\%]) of the patients were current smokers and the difference between sexes was significant (20 [60.6\%] females vs 33 [30.0\%] males, $P<0.01)$.

Blood pressure measurements exceeded guideline recommended target level in 37 (25.9\%) patients (Figure 2A), of whom the majority had only grade 1 hypertension. Among the patients not meeting the recommended guideline target, seven $(18.9 \%)$ received no antihypertensive treatment, while $18(48.7 \%)$ received two or more drug classes.

Plasma LDL-C concentrations were available in 133 patients (levels prior to lipid-lowering treatment were available in 75 patients), of whom 77 (57.9\%) did not reach LDL-C target levels. Thirty-five patients $(26.3 \%)$ had a plasma LDL-C concentration between 1.8 and $2.4 \mathrm{mM}, 25$ patients (18.8\%) between 2.5 and $2.9 \mathrm{mM}$, and 26 patients (19.6\%) had a LDL-C $\geq 3.0 \mathrm{mM}$. Among individuals not reaching the 
Table 2 Patient medication at study interview

\begin{tabular}{ll}
\hline Medication & Total patients $(\mathbf{n}=\mathbf{~ I 4 3 )}$ \\
\hline Platelet inhibitor or anticoagulant & $138(96.5)$ \\
Aspirin & $126(88.1)$ \\
ADP receptor blocker & $30(21.0)$ \\
Anticoagulant & $7(4.9)$ \\
Antihypertensive treatment & $114(79.7)$ \\
ACE-l/ARB & $66(46.2)$ \\
Beta-blocker & $92(64.3)$ \\
Calcium channel blocker & $35(24.5)$ \\
Diuretic & $26(18.2)$ \\
Lipid-lowering therapy & $121(84.6)$ \\
Statin & $119(83.2)$ \\
Ezetimibe & $20(14.0)$ \\
Fibrate & $2(1.4)$ \\
Other lipid-lowering drugs & $4(2.8)$ \\
Antidiabetic therapy (if known & $19(82.6)$ \\
diabetes, $n=23)$ & $8(34.8)$ \\
Metformin & $13(56.5)$ \\
Insulin & $4(17.4)$ \\
Other &
\end{tabular}

Note: Values are expressed as $\mathrm{n}(\%)$.

Abbreviations: ACE-I, angiotensin converting enzyme-inhibitor; ADP, adenosine diphosphate; ARB, angiotensin II receptor blocker.

Table 3 Risk factor control at study interview

\begin{tabular}{|c|c|c|c|c|}
\hline Risk factor & $\begin{array}{l}\text { Total } \\
(n=\mid 43)\end{array}$ & $\begin{array}{l}\text { Male } \\
(n=I \mid 0)\end{array}$ & $\begin{array}{l}\text { Female } \\
(n=33)\end{array}$ & $P$-value \\
\hline \multicolumn{5}{|l|}{ Treatment goals } \\
\hline High BPa & $37(25.9)$ & $29(26.4)$ & $8(24.2)$ & 0.81 \\
\hline Low HDL-C ${ }^{b}$ & $48(33.6)$ & $38(34.6)$ & $10(30.3)$ & 0.65 \\
\hline High LDL-Cc & 77 (57.9) & $59(58.4)$ & $18(56.3)$ & 0.83 \\
\hline High triglycerides ${ }^{d}$ & 67 (46.9) & $52(47.3)$ & $15(45.5)$ & 0.85 \\
\hline \multicolumn{5}{|l|}{ Lifestyle goals } \\
\hline Elevated $\mathrm{BMl}^{\mathrm{e}}$ & $113(79.0)$ & $93(84.6)$ & $20(60.6)$ & $<0.01$ \\
\hline Abd obesity ${ }^{f}$ & $76(53.2)$ & $57(5 \mid .8)$ & $19(57.6)$ & 0.56 \\
\hline Sedentary lifestyleg & $78(54.6)$ & $58(52.7)$ & $20(60.6)$ & 0.43 \\
\hline Current smoking ${ }^{\mathrm{h}}$ & $53(37.1)$ & $33(30.0)$ & $20(60.6)$ & $<0.01$ \\
\hline Metabolic syndrome & $68(47.6)$ & $51(46.4)$ & $17(5 \mid .5)$ & 0.60 \\
\hline
\end{tabular}

Notes: Values are expressed as $\mathrm{n}(\%)$. ${ }^{\mathrm{a} B P}$ threshold is $\geq 140 / 90 \mathrm{mmHg}$ except $\geq 140 / 80 \mathrm{mmHg}$ in diagnosed diabetics. 'bDL-C $<1.0 / 1.2 \mathrm{mM}(\mathrm{M} / \mathrm{F})$. ' $\mathrm{LDL}-\mathrm{C} \geq 1.8$ $\mathrm{mM}$ and $<50 \%$ of untreated value. Values were calculated in 133 patients and untreated values were only available in 75 patients. ${ }^{\text {TT Tiglycerides }} \geq 1.7 \mathrm{mM}$. ${ }^{\text {eBMI }}$ $\geq 25 \mathrm{~kg} / \mathrm{m}^{2}$. 'Waist circumference $\geq 102 / 88 \mathrm{~cm}(\mathrm{M} / \mathrm{F})$. ${ }^{8}$ Exercising $\geq 30$ minutes $<3$ times per week. "Smoking within the last month.

Abbreviations: Abd, abdominal; BMI, body mass index; BP, blood pressure; $F$, female; HDL-C, high-density lipoprotein cholesterol; LDL-C, low-density lipoprotein cholesterol; M, male.

recommended guideline target, $17(22.1 \%)$ were not receiving any lipid-lowering therapy while $52(67.5 \%)$ were on statin therapy only (Figure 2B), and only five (6.5\%) were treated with both a high-dose statin and other lipid-lowering therapy.

Diabetes was present in 29 (20.3\%) individuals, with ten (7.0\%) being diagnosed with type 1 diabetes, $13(9.1 \%)$ with type 2 diabetes, and six (4.2\%) having undiagnosed type 2 diabetes at study interview. Despite omitting patients with undiagnosed diabetes, $15(65.2 \%)$ had an $\mathrm{HbAlc}$ value $>53$ $\mathrm{mmol} / \mathrm{mol}$.

Sixty-eight (47.6\%) patients met the defined criteria for the metabolic syndrome. Patients with metabolic syndrome were less likely to report exercising 30 minutes $\geq 3$ times a week (19 [27.9\%] vs 46 [61.3\%], $P<0.01)$. Current smoking (24 [35.3\%] vs 29 [38.7\%], $P=0.68)$ and LDL-C control (25 [41.0\%] vs 31 [43.1\%], $P=0.67$ ), however, did not differ between patients with and without the metabolic syndrome.

In total, the median (IQR) number of uncontrolled health measures was $2(2 ; 4)$ (Figure 3). Seven (4.9\%) patients fulfilled all health measures. We found no difference in the number of uncontrolled risk factors between patients who attended regular CAD risk factor consultations and those who did not $(P=0.88)$.

\section{Discussion}

The primary findings of this study are as follows: 1) guideline-based risk factor control remains insufficient in young patients with CAD in spite of the fact that the majority attend regular health care control visits and are treated with antihypertensive and lipid-lowering medication. 2) We confirmed previous findings of a family history, obesity, and current/ former smoking as being common but added the metabolic syndrome as a common feature in young patients with CAD.

An association between adherence to risk factor control and a substantially lower incidence of cardiovascular disease has been demonstrated in several prospective cohort studies. ${ }^{11-13}$ Moreover, a number of studies have evaluated risk factor control in different study groups with or without a diagnosis of cardiovascular disease $e^{6,712,14,15}$ but not specifically addressing young patients with CAD. Results from the recent Euroaspire IV investigation ${ }^{7}$ showed some similarities to our results when comparing the strata of young patients with CAD. Despite variation in interview rates and risk factor distribution across countries, the average proportions obtained in the Euroaspire IV investigation ${ }^{7}$ about overweight/obesity (79.5\%/39.5\%), current smoking (33.6\%), and blood pressure control (26.3\%) were similar to our results, but LDL-C levels were more poorly controlled (83.3\% in Euroaspire IV had a LDL-C $\geq 1.8 \mathrm{mM}$ ). Furthermore, blood pressure target but not LDL-C or HbA1c targets were more commonly achieved in young patients compared with older patients. Another study directly compared risk factor control achievement in younger vs older patients participating in a cardiac rehabilitation program. In contrast, this study demonstrated that both LDL-C and systolic blood pressure targets were more commonly achieved in younger 

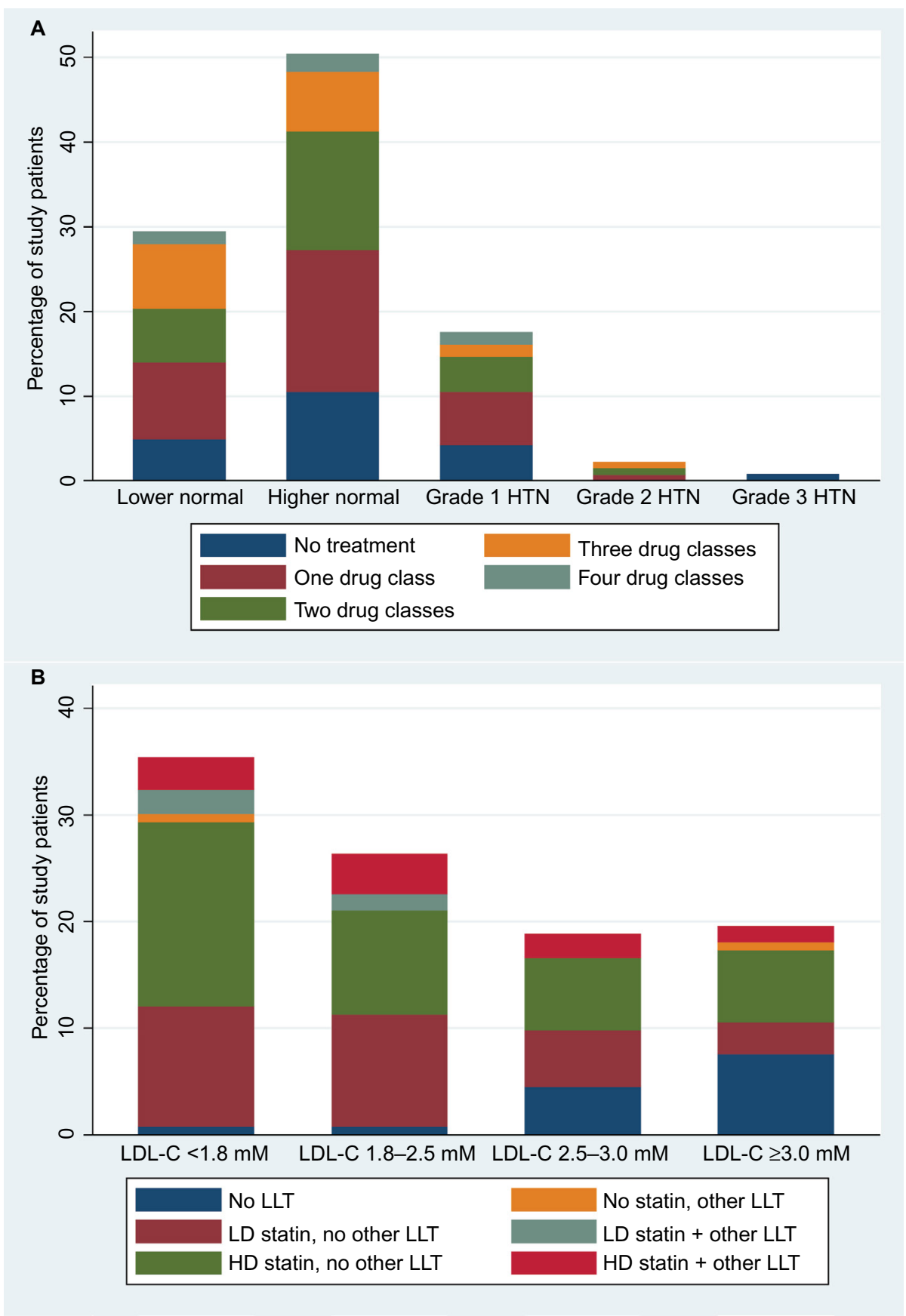

Figure 2 Blood pressure control and LDL-C control stratified by treatment in patients at study interview.

Notes: (A) Distribution of blood pressure levels and antihypertensive therapy within each category at study interview. Lower normal: $<120 / 80 \mathrm{mmHg}$. Higher normal: $<\mid 40 /<90 \mathrm{mmHg}$. Grade I HTN: <160/I00 mmHg. Grade $2 \mathrm{HTN}:<180 / 110 \mathrm{mmHg}$. Grade $3 \mathrm{HTN}$ : $\geq 180 / \mathrm{II} 0 \mathrm{mmHg}$. (B) Distribution of LDL-C levels and LLT within each category at study interview. LD statin: atorvastatin $<40 \mathrm{mg} /$ daily, rosuvastatin $<20 \mathrm{mg} /$ daily or another statin. HD statin: atorvastatin $\geq 40 \mathrm{mg} /$ daily or rosuvastatin $\geq 20 \mathrm{mg} /$ daily.

Abbreviations: HD, high-dose; HTN, hypertension; LD, low-dose; LDL-C, low-density lipoprotein cholesterol; LLT, lipid-lowering therapy.

patients at discharge. ${ }^{2}$ However, absolute differences between groups were modest and the high target achievement rates in such programs may not hold in the long run.

Several factors may explain the limited success in achieving risk factor control. The most common uncontrolled risk factors were adverse lifestyle habits, with the majority being overweight, exhibiting a sedentary lifestyle, and continued smoking. Even though the majority of patients attended regular health care visits and received antithrombotic, antihypertensive, and lipid-lowering therapy, a significant proportion did not reach individual blood pressure or lipid targets. One explanation may be that physicians did not react on deviations from target levels since $33(89.2 \%)$ patients not reaching blood pressure target had levels below 160/100 $\mathrm{mmHg}$ and 30 (39.0\%) of patients not 


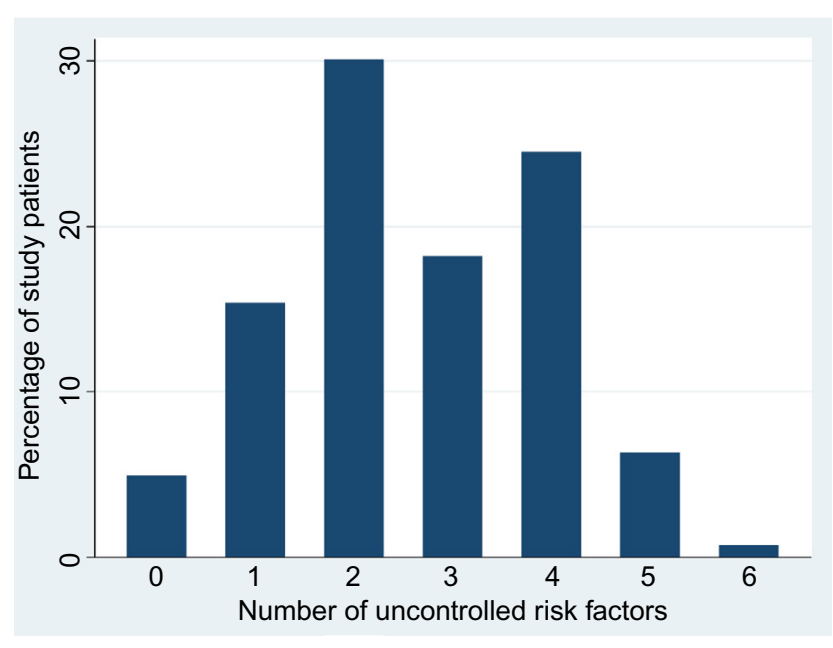

Figure 3 Distribution of the number of uncontrolled risk factors among patients at study interview.

reaching lipid targets had a LDL-C below $2.5 \mathrm{mM}$ measured at study interview. However, the benefits of reducing risk, even with an aggressive treatment strategy, are well documented, ${ }^{16,17}$ and in young patients with high lifetime risks of recurrent cardiovascular events, such a strategy should be pursued.

Almost three out of five patients did not reach the LDL-C target, more than one-half of the patients not reaching the target received no high-dose statin and 18 (23.4\%) patients not on target did not receive any statin therapy. Although statin therapy is generally considered effective, safe, and well tolerated, ${ }^{16,18}$ difficulties in achieving adherence to statin therapy have increased over the past decade, partly due to side effects and increasing media coverage. ${ }^{19}$ This may be a likely explanation for the high number receiving insufficient therapy. Moreover, high levels of physical activity and higher levels of alcohol intake, both of which are known to be risk factors for associated muscle symptoms, may be more common among younger individuals. ${ }^{20}$ However, it has been demonstrated that $>90 \%$ of the patients discontinuing statins due to side effects may tolerate the same or another statin. ${ }^{21}$ Additionally, only a minor proportion of patients received other lipid-lowering therapy. Hence, it seems reasonable to assume that lipidlowering therapy and intensity could be increased.

Notably, only eight (5.6\%) patients had genetically verified $\mathrm{FH}$, all of which had $L D L R$ mutations. The $L D L R$, $P C S K 9$ and $A P O B$ genes of ten other study patients with high levels of LDL-C were sequenced but none of them had genetic variants consistent with a diagnosis of monogenetic FH. The number of patients with FH was expected to be higher, given our age-criterion for inclusion and the fact that the prevalence of monogenetic $\mathrm{FH}$ is thought to be present in $\sim 5 \%$ of patients with CAD before the age of 60 years. ${ }^{22}$
Both overweight and a sedentary lifestyle are associated with the metabolic syndrome and diabetes, which are adversely related to cardiovascular disease risk and mortality. ${ }^{23}$ Though the reason for this association is complex, metabolic syndrome and diabetes cause coronary endothelial dysfunction; an early state preceding the manifestation of cardiovascular disease. ${ }^{24}$

In our study, the majority of patients were overweight and almost one-half of the patients fulfilled the used diagnostic criteria for metabolic syndrome. Estimates of the prevalence of the metabolic syndrome vary between studies, likely due to different definitions. A Norwegian study investigated the metabolic syndrome as defined by the International Diabetes Federation in a general population and found a prevalence of $28 \%$ and $22 \%$ among $40-49$-year-old males and females, respectively. ${ }^{25}$ The almost doubled prevalence of metabolic syndrome in our population may indicate that the composition of obesity and associated risk factors, including hypertension, dyslipidemia, and insulin resistance, may play a role in the development of CAD in young patients.

\section{Limitations}

The current single-center study is descriptive by nature and has no control group to allow for comparison with other patient groups, but consists of systematic and detailed data collected in all young patients with $\mathrm{CAD}$ treated at our tertiary center over more than a decade. A participation fraction of $50.5 \%$ is comparable to the results of the Euroaspire IV, ${ }^{7}$ but evidently this does not exclude selection bias. However, only the prevalence of family history of CAD was higher among study patients compared with eligible nonparticipating patients. The patients were offered a review of their medication and also to participate in genetic studies of CAD, which might have attracted patients with higher interest in disease prevention and self-care compared with patients declining participation. This would likely lead to an underestimation of uncontrolled risk factors. The clinical characteristics and risk factors at onset were retrospectively collected from medical files and therefore may not reflect those of the true eligible population. We used interviews to measure smoking habits and physical inactivity. The statements given by the patient were not questioned (eg, by breath carbon monoxide or pedometer measurements), which is a potential source of imprecision or bias on the estimates. The limited number of patients prompts a certain degree of imprecision on the estimates and also precludes any deeper analysis of the various strata of the data. The definition of metabolic syndrome was slightly modified, as fasting glucose was omitted as a criterion. Hence, the prevalence of the metabolic syndrome 
may likely be even higher than estimated. This change may hamper comparisons to other studies.

\section{Conclusion}

Among young patients with CAD, cardiovascular risk factors are common. A substantial potential for risk factor improvement remains. Studies to improve risk factor control and compliance improvement in young patients with CAD are needed.

\section{Acknowledgments}

The authors thank Karina Storgaard for helping with coordinating the clinical visits, and Jakob Hjort for providing assistance on the Western Denmark Heart Registry data acquisition. The authors acknowledge Amgen, King Christian IX and Queen Louise's Jubilee Foundation, Pfizer, Sanofi Aventis, and Snedkermester Sophus Jacobsen and Hustru Astrid Jacobsens Foundation who provided unrestricted grants for the research project.

\section{Disclosure}

JMJ reports personal fees from Bracco, outside the submitted work, and reports no other conflicts of interest in this work. HKJ reports grants from Pfizer, Amgen, and SanofiAventis during the conduct of the study, and reports no other conflicts of interest in this work. MKC, $\mathrm{AKB}$, and $\mathrm{HEB}$ report no conflicts of interest in this work.

\section{References}

1. Schoenenberger AW, Radovanovic D, Stauffer J-C, et al. AMIS Plus Investigators. Acute coronary syndromes in young patients: presentation, treatment and outcome. Int J Cardiol. 2011;148:300-304.

2. Reibis R, Treszl A, Wegscheider K, Bestehorn K, Karmann B, Völler H. Disparity in risk factor pattern in premature versus late-onset coronary artery disease: a survey of 15,381 patients. Vasc Health Risk Manag. 2012;8:473-481.

3. Risgaard B, Winkel BG, Jabbari R, et al. Burden of sudden cardiac death in persons aged 1 to 49 years: nationwide study in Denmark. Circ Arrhythm Electrophysiol. 2014;7:205-211.

4. Khawaja FJ, Rihal CS, Lennon RJ, Holmes DR, Prasad A. Temporal trends (over 30 years), clinical characteristics, outcomes, and gender in patients $\leq 50$ years of age having percutaneous coronary intervention. Am J Cardiol. 2011;107:668-674.

5. Perk J, De Backer G, Gohlke H, et al. European Association for Cardiovascular Prevention \& Rehabilitation (EACPR), ESC Committee for Practice Guidelines (CPG). European Guidelines on cardiovascular disease prevention in clinical practice (version 2012). The Fifth Joint Task Force of the European Society of Cardiology and other societies on cardiovascular disease prevention in clinical practice (constituted by representatives of nine societies and by invited experts). Eur Heart J. 2012;33:1635-1701.

6. Paixao ARM, Enriquez JR, Wang TY, et al. Risk factor burden and control at the time of admission in patients with acute myocardial infarction: results from the NCDR. Am Heart J. 2015;170:173-179.e1.

7. Kotseva K, Wood D, De Bacquer D, et al. EUROASPIRE Investigators. EUROASPIRE IV: a European Society of Cardiology survey on the lifestyle, risk factor and therapeutic management of coronary patients from 24 European countries. Eur J Prev Cardiol. 2016;23(6):636-648.
8. The Danish National Institute of Public Health. The Danish Health and Morbidity Survey 2005 [Internet]; 2006 [cited October 23, 2015]:1-72. Available from: http://si-folkesundhed.dk/upload/personligt_interviewskema_med_svarfordeling_-_2005.pdf. Accessed October 23, 2015.

9. Myers MG, Godwin M, Dawes M, Kiss A, Tobe SW, Kaczorowski J. Conventional versus automated measurement of blood pressure in the office (CAMBO) trial. Family Pract. 2012;29:376-382.

10. Alberti KGMM, Zimmet P, Shaw J. Metabolic syndrome - a new worldwide definition. A consensus statement from the International Diabetes Federation. Diabet Med. 2006;23:469-480.

11. Akesson A, Weismayer C, Newby PK, Wolk A. Combined effect of lowrisk dietary and lifestyle behaviors in primary prevention of myocardial infarction in females. Arch Intern Med. 2007;167:2122-2127.

12. Yang Q, Cogswell ME, Flanders WD, et al. Trends in cardiovascular health metrics and associations with all-cause and CVD mortality among US adults. JAMA. 2012;307:1273-1283.

13. Akesson A, Larsson SC, Discacciati A, Wolk A. Low-risk diet and lifestyle habits in the primary prevention of myocardial Infarction in males: a population-based prospective cohort study. J Am Coll Cardiol. 2014;64:1299-1306.

14. Farkouh ME, Boden WE, Bittner V, et al. Risk factor control for coronary artery disease secondary prevention in large randomized trials. $\mathrm{J} \mathrm{Am}$ Coll Cardiol. 2013;61:1607-1615.

15. Tully L, Gianos E, Vani A, et al. Suboptimal risk factor control in patients undergoing elective coronary or peripheral percutaneous intervention. Am Heart J. 2014;168:310-316.e3.

16. Cholesterol Treatment Trialists' (CTT) Collaboration, Baigent C, Blackwell L, Emberson J, et al. Efficacy and safety of more intensive lowering of LDL cholesterol: a meta-analysis of data from 170,000 participants in 26 randomised trials. Lancet. 2010;376:1670-1681.

17. Blood Pressure Lowering Treatment Trialists' Collaboration, Sundström $\mathrm{J}$, Arima H, Woodward M, et al. Blood pressure-lowering treatment based on cardiovascular risk: a meta-analysis of individual patient data. Lancet. 2014;384:591-598.

18. Task Force for the management of dyslipidaemias of the European Society of Cardiology (ESC) and the European Atherosclerosis Society (EAS), Catapano AL, Reiner Z, De Backer G, et al. ESC Committee for Practice Guidelines 2008-2010 and 2010-2012 Committees. ESC/ EAS Guidelines for the management of dyslipidaemias: the Task Force for the management of dyslipidaemias of the European Society of Cardiology (ESC) and the European Atherosclerosis Society (EAS). Atherosclerosis. 2011;217 (Suppl 1):S1-44.

19. Stroes ES, Thompson PD, Corsini A, et al. European Atherosclerosis Society Consensus Panel. Statin-associated muscle symptoms: impact on statin therapy-European Atherosclerosis Society Consensus Panel Statement on Assessment, Aetiology and Management. Eur Heart J. 2015;36:1012-1022.

20. Mancini GBJ, Tashakkor AY, Baker S, et al. Diagnosis, prevention, and management of statin adverse effects and intolerance: Canadian Working Group Consensus update. Can J Cardiol. 2013;29(12):1553-1568.

21. Zhang H, Plutzky J, Skentzos S, et al. Discontinuation of statins in routine care settings: a cohort study. Ann Intern Med. 2013;158: 526-534.

22. Goldstein JL, Brown MS. The LDL receptor. Arterioscler Thromb Vasc Biol. 2009;29:431-438.

23. Malik S, Wong ND, Franklin SS, et al. Impact of the metabolic syndrome on mortality from coronary heart disease, cardiovascular disease, and all causes in United States adults. Circulation. 2004;110:1245-1250.

24. Ciccone MM, Scicchitano P, Cameli M, et al. Endothelial function in pre-diabetes, diabetes and diabetic cardiomyopathy: a review. J Diabetes Metab. 2014;5:1-10.

25. Hildrum B, Mykletun A, Hole T, Midthjell K, Dahl AA. Age-specific prevalence of the metabolic syndrome defined by the International Diabetes Federation and the National Cholesterol Education Program: the Norwegian HUNT 2 study. BMC Public Health. 2007;7:220. 


\section{Supplementary material}

Table SI Comparison between eligible patients and eligible nonparticipants based on the first registered coronary intervention between 2002 and 2013

\begin{tabular}{|c|c|c|c|}
\hline Characteristics & $\begin{array}{l}\text { Patients } \\
(n=\mid 43)\end{array}$ & $\begin{array}{l}\text { Eligible } \\
\text { nonparticipants } \\
(n=140)\end{array}$ & $P$-value \\
\hline Age $\mathrm{e}^{\mathrm{a}}$ years & $37(35 ; 38)$ & $37(34 ; 38)$ & 0.98 \\
\hline \multirow[t]{2}{*}{ Male } & $110 / 143$ (76.9) & $104 / 140(74.3)$ & 0.61 \\
\hline & & & 0.97 \\
\hline First registered procedure & & & 0.97 \\
\hline $\mathrm{PCl}$ & |37/| 43 (95.8) & $134 / 140$ (95.7) & \\
\hline CABG & $6 / 143(4.2)$ & $6 / 140(4.3)$ & \\
\hline $\mathrm{PCl}$ indication & & & 0.78 \\
\hline STEMI & $76 / 137(55.5)$ & $70 / 134(52.2)$ & \\
\hline NSTEMI & $30 / 137(21.9)$ & $31 / 134(23.1)$ & \\
\hline UAP & $\mathrm{I} / \mathrm{I} 37(0.7)$ & $\mathrm{I} / \mathrm{I} 34(0.8)$ & \\
\hline SAP & $29 / 137(21.2)$ & $28 / 134(20.9)$ & \\
\hline Other & $\mathrm{I} / \mathrm{I} 37(0.7)$ & $4 / 134(3.0)$ & \\
\hline Diseased vessels & & & 0.72 \\
\hline \multicolumn{4}{|l|}{ (PCl-patients only) } \\
\hline IVD & $84 / 106$ (79.3) & $83 / 104(79.8)$ & \\
\hline $2 \mathrm{VD}$ & $12 / 106(11.3)$ & $14 / 104$ (13.5) & \\
\hline $3 \mathrm{VD}$ & $10 / 106(9.4)$ & $7 / 104(6.7)$ & \\
\hline Family history & $86 / 134(64.2)$ & $63 / 127(49.6)$ & 0.02 \\
\hline Treatment of hypertension & $21 / 139(15.1)$ & $18 / 135(13.3)$ & 0.67 \\
\hline Treatment of dyslipidemia & $48 / 140(34.3)$ & $44 / 135(32.6)$ & 0.77 \\
\hline Diabetes & $14 / 134(10.5)$ & $20 / 135(14.8)$ & 0.28 \\
\hline Current smoking & $1 \mathrm{I} / / \mathrm{I} 34(82.8)$ & $110 / 133(82.7)$ & 0.98 \\
\hline BMI $\left(\mathrm{kg} / \mathrm{m}^{2}\right)^{\mathrm{b}}$ & $27.7(24.9 ; 31.1)$ & $27.4(24.8 ; 31.6)$ & 0.98 \\
\hline Creatinine $(\mu M)^{c}$ & $74(65 ; 85)$ & $75(66 ; 85)$ & 0.74 \\
\hline
\end{tabular}

Notes: Values are expressed as median (IQR) or $\mathrm{n} / \mathrm{N}$ (\%). ${ }^{\mathrm{a} D a t a}$ available for all patients and eligible nonparticipants. ${ }^{b}$ Data available for 99 patients and $10 \mathrm{I}$ eligible nonparticipants. 'Data available for 67 patients and 75 nonparticipants.

Abbreviations: BMI, body mass index; $\mathrm{CABG}$, coronary artery bypass graft; $\mathrm{IQR}$, interquartile range; NSTEMI, non-ST-elevation myocardial infarction; PCl, percutaneous coronary intervention; SAP, stable angina pectoris; STEMI, ST-elevation myocardial infarction; UAP, unstable angina pectoris; VD, vessel disease.

Vascular Health and Risk Management

\section{Publish your work in this journal}

Vascular Health and Risk Management is an international, peerreviewed journal of therapeutics and risk management, focusing on concise rapid reporting of clinical studies on the processes involved in the maintenance of vascular health; the monitoring, prevention and treatment of vascular disease and its sequelae; and the involvement of

\section{Dovepress}

metabolic disorders, particularly diabetes. This journal is indexed on PubMed Central and MedLine. The manuscript management system is completely online and includes a very quick and fair peer-review system, which is all easy to use. Visit http://www.dovepress.com/ testimonials.php to read real quotes from published authors. 